\title{
Exploring occupational therapy graduates' conceptualisations of occupational justice in practice: Curriculum implications
}

\author{
L A Hess-April, ${ }^{1} \mathrm{PhD}$; J Smith, ${ }^{2} \mathrm{PhD} ; \mathrm{J}$ de Jongh, ${ }^{1} \mathrm{PhD}$ \\ ${ }^{1}$ Department of Occupational Therapy, Faculty of Community and Health Sciences, University of the Western Cape, Cape Town, South Africa \\ ${ }^{2}$ Department of Educational Studies, Faculty of Education, University of the Western Cape, Cape Town, South Africa
}

Corresponding author: L A Hess-April (lhess@uwc.ac.za)

Background. The concept of occupational justice was derived from a social justice perspective in response to a renewed commitment by the occupational therapy profession to address the occupational needs of individuals, groups and communities who experience social injustice. Accordingly, it is acknowledged that education with regard to occupational justice has the deliberate intention of preparing graduates, who would be change agents as critical practitioners. Nonetheless, while occupational therapy education programmes may seek to instil broader professional values, theory covered in the curriculum may not always assure congruent practice.

Objective. To explore how occupational therapy graduates' conceptualisations of occupational justice, as instilled by the occupational therapy curriculum of the University of the Western Cape, South Africa, manifested in their practice while undergoing community service.

Methods. Seven occupational therapy graduates were selected to participate in the study through purposive sampling. A descriptive case study of their practice was generated through qualitative methods. Semi-structured interviews, document review and participant observation were used as data collection methods, analysed through a process of inductive thematic analysis.

Results. The findings revealed that while the participants conceptualised occupational justice as broader social change through occupational enablement, they encountered several constraints related to structural and systemic power issues in their practice contexts.

Conclusion. The study supports the utilisation of transformative learning and inter-professional education in developing critical competencies such as agency and political proficiency to assist graduates in dealing with the complexities of practice during community service.

Afr J Health Professions Educ 2016;8(2):189-192. DOI:10.7196/AJHPE.2016.v8i2.609

In the past decade, developments within the occupational therapy profession led to a critique of reductionist approaches that retained practice in traditional biomedical settings and the adoption of knowledge frameworks responsive to community needs. It was acknowledged that as a basic human need occupation is crucial for health and wellbeing. ${ }^{[1]}$ Accordingly, the concept of occupation, as understood in the profession, evolved from therapeutic activity (within a medical model approach) to occupational enablement as a principle of occupational justice (within a sociopolitical approach). Considering that some people are privileged to choose what they do, while others are deprived of occupational choice, the central point in the theoretical construct of occupational justice is that injustice results when people are restricted from engaging in occupation. ${ }^{[2]} \mathrm{An}$ occupationally just society is therefore viewed as one in which people's occupational rights are met, and in which they are empowered to choose and perform occupations according to their own needs or wants. ${ }^{[2]}$ Consequently, there were calls for occupational therapy education programmes to become more responsive to the local context, and to facilitate graduate attributes such as resilience ${ }^{[3]}$ and critical reflexivity. ${ }^{[4]}$ This resulted in a global reorientation of the profession that, coupled with health and education reform in South Africa (SA), gave momentum to the development of the University of the Western Cape (UWC) occupational therapy curriculum to one with a critical orientation. ${ }^{[5]}$

A number of factors may inhibit occupational therapists' ability to promote occupational justice in everyday practice. Méthot ${ }^{[6]}$ is of the opinion that the occupational therapy profession's emphasis on the promotion of occupational justice may be at odds with the curative approach of the medical model that, in some instances, is still dominant in healthcare. Likewise, Wilding's $\mathrm{s}^{[7]}$ study on occupational therapists' experiences in a hospital setting showed that the dominant discourse of medical epistemology acted as a form of hegemony that manifested in the therapists' unconscious compliance with the protocols of the hospital, thus hindering occupation-based practice. With regard to practice context, Newton and Fuller ${ }^{[8]}$ identified that occupational therapists who work in rural and remote areas may encounter challenges, such as professional isolation, as interprofessional networks may be non-existent and they therefore may not be able to form collaborations and alliances to support their practice.

It has been suggested that occupational therapy education programmes facilitate students' ability to examine institutional systems that hinder occupational justice, and their ability to advocate for systemic and structural changes that would facilitate it, ${ }^{\left[{ }^{[0]}\right.}$ highlighting the importance of critical consciousness. ${ }^{[5]}$ One teaching and learning approach that has been singled out as a doorway to critical consciousness is transformative learning. ${ }^{[10]}$ The facilitation of critical reflexivity as a teaching and learning approach is central to transformative learning, as it entails a process by which assumptions are brought to light, clarified and challenged to generate beliefs to guide action. ${ }^{[10]}$ Julio et al. ${ }^{[11]}$ describe the essence of transformative learning as developing students' leadership attributes and producing enlightened change agents. In addition to transformative learning, they emphasise the importance of interprofessional education in fostering joint solutions to health issues and the transformation of health systems.

The influence of a truly critical curriculum would be exhibited by its graduates through their own empowerment beyond the confines of the university. ${ }^{[12]}$ Uncovering graduates' conceptualisations of occupational justice and its translation into practice could therefore illuminate developments in the curriculum that may be required to address the critical competencies of students. This article reports on a broader study that aimed to explore how 
UWC occupational therapy graduates' conceptualisations of occupational justice manifest in their practice. In particular, we discuss one of the objectives of the study, i.e. to reflect on strategies that could be employed to address constraints faced by UWC community service occupational therapy graduates in incorporating occupational justice into their practice.

\section{Methods}

A qualitative research approach was adopted to generate a case study of the practice of a group of UWC graduates who were performing community service. Qualitative research is fundamentally interpretive, with the primary objective of comprising in-depth description and understanding. ${ }^{[13]}$ The objective of the study was to explore how UWC occupational therapy graduates' conceptualisations of occupational justice manifest in their practice. A descriptive case study design was therefore appropriate.

\section{Data collection and procedures}

Purposive sampling was used to recruit seven graduates who had at least 6 months of community service experience in 2010. Graduates in underresourced, rural practice contexts were selected in line with the purpose of the community service policy to increase availability and access to health services in these contexts. Selection was further based on the service level where they were placed for community service.

Data collection methods included document review that provided background information on the participants' practice; participant observation that was utilised to gain an understanding of their practice contexts; and semi-structured interviews that allowed them to reflect on their understanding and enactment of occupational justice in practice and on the influence of their education on their practice. Initial interviews, between 45 minutes and 1 hour in duration, were conducted during the period of participant observation, while follow-up interviews that lasted for $\sim 1$ hour were conducted after the completion of data analysis to allow for a deeper probing of the research issues. To prompt reflection, a set of predetermined questions was developed as a guide (Table 1) and used in a flexible manner.

Inductive thematic data analysis was used to analyse the data. Trustworthiness was ensured through triangulation, a detailed description of the research context and process, peer examination, and maintaining a reflective journal. Once the data were transcribed and analysed, the participants had an opportunity to check the accuracy of the findings, engage with the analysis, and further reflect on the curriculum in relation to its tenet of occupational justice.

Ethical clearance was obtained from the UWC Research Committee (No. 10/4/25) and the respective provincial health research ethics committees. Informed written consent was obtained from all participants. They could withdraw their participation at any stage without being penalised, and issues of confidentiality and anonymity were adhered to. In conducting participant observation, informed consent was obtained from all persons with whom the participants interacted at that particular time.

\section{Results}

The participants practised in settings where health problems were described as typical of a developing context, as these were characterised by poor socioeconomic conditions. Six of the seven participants were placed at district hospitals. The primary responsibility of the participants was to provide clinical occupational therapy services, with individual interventions as the focal mode of practice. Only two participants were involved in community projects, while the others engaged in community activities on their own initiative, as it was not expected of them. Table 2 provides a description of the participants' practice contexts, settings and roles.

Table 1. Interview guide

\section{Questions}

Can you describe the kind of OT you are, or that you identify with?

Why are you thinking in this way?

What is the role of the OT in this setting?

What is your particular vision for the role of $\mathrm{OT}$ in the setting?

How have you come to this vision?

How do you understand occupational justice and how have you incorporated it into your practice? What have been some constraints or challenges, if any, you experience in practising in this setting? How have you responded to these constraints/challenges?

Can you describe some interventions you've participated in that you would say exemplify how you integrate your education about OT with what you do in practice?

$\mathrm{OT}=$ occupational therapist.

Table 2. Participants' practice contexts, settings and roles

\begin{tabular}{|c|c|c|c|}
\hline Participant & Province & Practice setting & Primary roles \\
\hline 1 & Northern Cape & $\begin{array}{l}\text { Department of Health } \\
\text { district office }\end{array}$ & $\begin{array}{l}\text { Clinic/hospital individual consultations } \\
\text { Health-promotion groups } \\
\text { Home visits }\end{array}$ \\
\hline 2 & Western Cape & Community health centre & $\begin{array}{l}\text { Individual consultations } \\
\text { Weekly clinics } \\
\text { Health-promotion groups } \\
\text { Home visits } \\
\text { Health forum meetings } \\
\text { Community outreach and support }\end{array}$ \\
\hline 3 & Eastern Cape & District hospital & $\begin{array}{l}\text { Individual consultations } \\
\text { Disability grant assessments } \\
\text { Rehabilitation meetings } \\
\text { Cerebral palsy groups }\end{array}$ \\
\hline 4 & Eastern Cape & District hospital & $\begin{array}{l}\text { Individual consultations } \\
\text { Disability grant assessments } \\
\text { Rehabilitation meetings }\end{array}$ \\
\hline 5 & Northern Cape & District hospital & Individual consultations \\
\hline 6 & Northern Cape & District hospital & Individual consultations \\
\hline 7 & Western Cape & Regional hospital & $\begin{array}{l}\text { Individual consultations } \\
\text { In-patient groups } \\
\text { Rehabilitation meetings }\end{array}$ \\
\hline
\end{tabular}


Two themes that illustrate how the participants conceptualised occupational justice and the factors that curtailed their efforts to promote it in practice emerged from the findings: (i) the meaning of occupational justice; and (ii) contextual constraints to occupational justice (Table 3).

\section{Theme 1}

The meaning of occupational justice captures the participants' understanding of it as broader social change and an outcome of people's occupational enablement. It is supported by two categories, i.e. health and wellbeing through social change, and social change through occupational enablement.

Health and wellbeing through social change illustrates that the extent to which people have opportunities, resources and skills for occupational engagement informed the participants' conceptualisations of occupational justice. The interviews illuminated an understanding that occupation, e.g. play in children, was important for their health and wellbeing. Therefore, in addition to addressing biological problems, the occupational therapy role also entailed addressing social issues that affect people's occupational performance.

Social change through occupational enablement points to the value that the participants assigned to taking cognisance of the influence of context on occupational participation. Hence, their reflections revealed insight into the conditions of people's lives and the understanding that occupational enablement needs to extend beyond hospital borders.

\section{Theme 2}

Contextual constraints to occupational justice capture systemic and educational factors that influenced the participants' practice. It is supported by four categories, i.e. occupational therapy vision does not fit the system; resource constraints; complex process of bureaucracy; and practice-education gaps (Table 4).

That the occupational therapy vision does not fit the system illustrates that the participants perceived the medical model to be dominant in their practice settings and that other health professionals lacked awareness of occupational therapy. Consequently, they felt that the health system did not accommodate their vision of occupational enablement.

Resource constraints capture constraints to practise encountered by the participants, such as a lack of resources for materials to assist clients

Table 3. Quotations in support of the categories of theme 1: Meaning of occupational justice

\begin{tabular}{ll}
\hline Category & Quotations \\
$\begin{array}{l}\text { Health and } \\
\text { wellbeing through } \\
\text { social change }\end{array}$ & $\begin{array}{l}\text { 'We saw that the kids did not engage in any occupational activities, we explained to } \\
\text { them [the caregivers] the importance of occupation ... that the occupations of the } \\
\text { children are play and education and we reflected on how we could make a difference.' } \\
\text { 'Children play as their primary occupation so it's equipping the teachers with skills ... } \\
\text { developing personal skills so that they can deliver a better service to the children.' }\end{array}$ \\
$\begin{array}{l}\text { Social change } \\
\text { through occupational } \\
\text { enablement }\end{array}$ & $\begin{array}{l}\text { 'The medical is obviously important ... but you can't send patients back to the community } \\
\text { 'When I have a session with the client I ask if the wheelchair will fit through the } \\
\text { door ... is it possible to make a path or a ramp ... the question is: can it the } \\
\text { wheelchair] really be used ... can it be used in the context?' }\end{array}$
\end{tabular}

Table 4. Quotations in support of the categories of theme 2: Contextual constraints to occupational justice

\begin{tabular}{ll}
\hline Category & Quotations \\
\hline $\begin{array}{l}\text { Occupational } \\
\text { therapy vision does } \\
\text { not fit the system }\end{array}$ & $\begin{array}{l}\text { 'It is very medically orientated ... very clinical ... they expect you to only work } \\
\text { with kids who have learning problems or you work with hands or strokes ... . }\end{array}$ \\
& 'They [staff] have poor understanding of the service that we provide ... that is ... \\
vesource & 'You big barrier for us.' \\
constraints & $\begin{array}{l}\text { about resources, because sometimes you just don't have any resources to work with. } \\
\text { 'We use our own money. The other day, we were in this mobile ... [giggles] ... }\end{array}$ \\
& just said ... as long as it takes us from point A to point B we will sit at the back.'
\end{tabular}

Complex process 'There's that barrier between the health and the education department ... you of bureaucracy don't have connections with each other ... we went to the schools and were told that we are not allowed to.'

'If I must ask where this workshop fits in she [senior OT] will say admin and it is not really admin because it is community outreach but at the end of the day the [management] want statistics.'

Practice-education 'As professionals we should be confident in building collaboration and build gaps alliances with the most influential groups in the community who can support us.' 'T've gone through a little depression because I was thinking of everything that we were taught and how passionate we were at university ... I feel that I am not doing enough.

to practise their occupations, and a lack of transport for community outreach. The participants, however, articulated that they used personal resources and were determined to succeed.

The complex process of bureaucracy shows that the participants perceived issues of bureaucracy to hinder their efforts at providing community practice and to prohibit the accurate recording of statistics for services provided through community outreach.

Lastly, practice-education gaps point to the participants' articulated feelings of despondency that resulted in a lowered sense of morale because of a perceived lack of ability and confidence to engage in interprofessional practice, build collaborations, and practise occupational therapy according to the way in which they were educated, indicating an apparent gap between their practice and their education.

\section{Discussion}

With the purpose of generating an understanding of the graduates' perspectives and practice experiences with regard to occupational justice to inform the undergraduate curriculum, this study explored new occupational therapy graduates' conceptualisations and enactments of occupational justice while undergoing compulsory community service. The participants shared a knowledge base by virtue of their status as UWC graduates and by being guided by the philosophies of the occupational therapy profession. This was evident in the manner in which they held the belief that there is a relationship between 
health, wellbeing and occupational engagement, and that occupational participation is contextual. ${ }^{[1]}$ Informed by this belief, they worked to advance occupational justice, which they conceptualised as enhanced wellbeing and broader social change as outcomes of occupational enablement. ${ }^{[2]}$ However, the participants experienced many constraints to practise, including a lack of occupational therapy awareness, difficulty collaborating with other professionals, and systemic factors such as medical model dominance, lack of resources and a complex system of bureaucracy.

The challenges encountered concur with those identified by occupational therapists who practise in rural contexts ${ }^{[8]}$ and settings where the medical model dominates. ${ }^{[6,7]}$ The participants did not appear to be able to effectively address these challenges, thus alerting to a lack of agency and ability to respond to the complexities of community service practice. It appears that they may have experienced a sense of powerlessness, evident in their low sense of morale due to their inability to bring their occupational therapy vision to reality.

Although they may have had similar educational experiences, the interpretation of these constraints would be different for each participant owing to their individual life experiences and variations in their own world. Furthermore, as novice practitioners they left behind the educational setting in which their particular occupational therapy knowledge was constructed and entered a health service that portrayed its own socially constructed knowledge. Consequently, it appears that the participants experienced value discrepancies between the knowledge constructed by means of their education and the knowledge system they encountered in their practice contexts. This dissonance left them with a sense of despondency towards the constraints they encountered.

It is important to consider to what extent the findings illustrate competencies, such as political proficiency ${ }^{[4]}$ and critical reflexivity, ${ }^{[5,10]}$ in judging to what extent the participants were able to work towards occupational justice. While the participants were critical about systemic factors that impacted people's occupational wellbeing, they seemed unable to engage in actions to address these factors. The complexities of community service practice require graduates to recognise the dynamics that operate within this context and to identify and implement strategies to work proactively within the limitations or opportunities imposed by these dynamics. Inferred here is the importance of critical reflexivity to stimulate awareness of self and contexts, which in turn foster critical consciousness, thereby motivating critical or transformative action. ${ }^{[5]} \mathrm{A}$ lack of critical reflexivity regarding power dynamics could therefore have led to participants' failure to actively address occupational justice.

\section{Curriculum implications}

Transformative learning ${ }^{[10]}$ could provide students with a more in-depth approach to critical reflection and develop their critical consciousness. Educators would have to facilitate a level of reflexivity that interrogates questions such as: how do different forms of power in my practice context influence me and my practice?; and what strategies could I use to challenge power dynamics? Through the use of this critical lens, visions of possibilities for change, ${ }^{[5]}$ supporting the development and implementation of critical actions towards realising these possibilities could be identified. To further students' ability to engage in a possibilities-based practice, Griffin ${ }^{[14]}$ suggests the development of skills such as negotiation and conflict resolution, and those influencing decision-making within the healthcare system. Similarly, Kronenberg et al. ${ }^{[9]}$ name skills such as creative networking, writing proposals and political lobbying as requisites for occupational therapists to shape and influence the face of healthcare in SA. Other examples might be teaching students how to write submissions for change or conduct action research projects that deal with occupational justice issues. ${ }^{[9]}$

The importance of interprofessional practice is also highlighted by this study. The findings support the importance of collaborative practice in increasing the relevance of healthcare services. ${ }^{[15]}$ Accordingly, the integration of interprofessional education in occupational therapy curricula may facilitate health professions graduates' understanding of the role of occupational therapists and other team members, and facilitate the development of positive attitudes towards collaboration.

\section{Study limitations}

It is a limitation of this study that formal feedback regarding the participants' role in practice was not sought from their respective employers, managers, colleagues and users of occupational therapy services. Such feedback is indeed worthy of future research.

\section{Conclusion}

This study highlights that for occupational therapy graduates to influence the contexts in which they practise in SA, occupational therapy education must ensure that students not only accumulate core occupational therapy knowledge, but are equipped to advance occupational justice in challenging practice environments. To reach this goal, transformational learning as pedagogical practice could be instrumental, as it frames student preparation not just as learning but as a process that equips students to intervene in matters of social and occupational justice as active agents of change. It is furthermore imperative that occupational therapy curricula facilitate interprofessional education and practice to develop graduates' competencies in forming alliances and collaborations in addressing health outcomes.

Acknowledgement. The National Research Foundation financially supported this study, but did not influence the research process or this article.

\section{References}

1. Wilcock A. An Occupational Perspective of Health. 2nd ed. Thorofare, NJ: Slack, 2006.

2. Townsend E, Wilcock A. Occupational justice and client-centered practice: A dialogue in progress. Can J Occup Ther 2004;71(2):75-87. DOI:10.1177/000841740407100203

3. Buchanan H, Cloete L. Preparing students for the complexities of practice learning. In: Lorenzo T, Duncan M Buchanan H, Alsop A, eds. Practice and Service Learning in Occupational Therapy: Enhancing Potential in Context. London: John Wiley, 2006;71-87.

4. Duncan M, McMillan W. A responsive curriculum for new forms of practice, education and learning. In: Lorenzo T, Duncan M, Buchanan H, Alsop A, eds. Practice and Service Learning in Occupational Therapy: Enhancing Potential in Context. London: John Wiley, 2006:7-19.

5. Freire P. Pedagogy of the Oppressed. London: Penguin, 1996.

6. Méthot D. Capacity and competency, collaboration and communication: A road map for the future. Can J Occup Ther 2004;71(4):197-201. DOI:10.1177/000841740407100402

7. Wilding C. Raising awareness of hegemony in occupational therapy: The value of action research for improving practice. Aust Occup Ther J 2011;58(4):293-299. DOI:10.1111/j.1440-1630.2010.00910.x

practice. Aust Occup Ther 2011,58(4):293-299. DO10.111/.10 New E, Fuller B. The occupational therapy international oction therapists working withou borders. In: Krony ingerg $\mathrm{F}$, Algado S, Pollard N, eds. Occupational Therapy 9. Kithout Bor Fe Lean . Kronenberg F, Pollard N, Ramugondo E. Introduction: Courage to dance politics. In: Kronenberg F, Pollard N Sakellariou D, eds. Occupational Therapies without Borders, vol. 2: Towards Ecology of Occupation-Based Practices. Edinburgh: Churchill Livingstone, 2011:1-16.

0. Mezirow J. Transformative Dimensions of Adult Learning. San Francisco, CA: Jossey-Bass, 1991

11. Julio F, Chen L, Bhutta ZA, et al. Health professionals for a new century: Transforming education to strengthen health systems in an interdependent world. Lancet 2010;376(9756):1923-1958. DOI:10.1016/s0140-6736(10)61854-5

12. Freire P, Shor I. A Pedagogy for Liberation: Dialogues for Transforming Education. South Hadley, MA: Bergin and Garvey, 1987.

13. Babbie E, Mouton J. Qualitative studies. In: Babbie E, Mouton J, eds. The Practice of Social Research. Cape Town: Oxford University Press, 2001:269-312.

14. Griffin S. Occupational therapists and the concept of power: A review of the literature. Aust Occup Ther 2001;48(1):24-34. DOI:10.1111/j.1440-1630.2001.00231.x

15. World Health Organization. Transforming and Scaling Up Health Professionals' Education and Training. Geneva: WHO, 2013. 